\title{
ОЦЕНКА ВКЛАДА ПОЛИМОРФИЗМА ОКИСЛИТЕЛЬНОГО МЕТАБОЛИЗМА В РЕАЛИЗАЦИЮ ВЫРАЖЕННОСТИ ФАРМАКОДИНАМИЧЕСКОГО ЭФФЕКТА КОМБИНИРОВАННОЙ АНТИГИПЕРТЕНЗИВНОЙ ТЕРАПИИ
}

\author{
(C) Гридина С.А. ${ }^{1}$, Поветкин С.В. ${ }^{2}$, Григорьева T.M. ${ }^{3}$ \\ ${ }^{1}$ Областной клинический противотуберкулезный диспансер, Курск; \\ ${ }^{2}$ кафедра клинической фармакологии, ${ }^{3}$ кафедра общей и биоорганической химии \\ Курского государственного медицинского университета, Курск \\ E-mail: clinfarm@kursknet.ru
}

\begin{abstract}
Целью работы являлась оценка влияния фенотипа окислительного метаболизма на выраженность фармакодинамического эффекта многоступенчатой гипотензивной терапии, проводимой у больных артериальной гипертонией высокого и очень высокого риска. В исследование было включено 120 больных артериальной гипертонией 2-3 степени. Высокий риск развития сердечно-сосудистых осложнений был определен у 58 чел. (48,3\%), очень высокий у 62 больных (51,7\%). Результаты проведенного исследования показали наличие зависимости степени снижения артериального давления от фенотипического варианта окислительного метаболизма, оцениваемой при 14-недельном лечении больных артериальной гипертонией различными схемами многоступенчатой гипотензивной терапии с включением амлодипина в качестве стартового препарата. Данный факт может позволить проводить индивидуализированный выбор начального варианта фармакотерапии пациентов с артериальной гипертонией.
\end{abstract}

Ключевые слова: артериальная гипертония, фармакокинетика, комбинированная фармакотерапия.

\section{ASSESSMENT OF CONTRIBUTING POLYMORPHISM OF OXIDATIVE METABOLISM TO REALIZATION OF INTENSITY OF PHARMAKODYNAMIC EFFECT OF THE COMBINED ANTIHYPERTENSIVE THERAPY Gridina S.A. ${ }^{l}$, Povetkin S. V. ${ }^{2}$, Grigorieva T.M. ${ }^{3}$ \\ ${ }^{1}$ Regional Clinical TB Dispensary, Kursk; ${ }^{2}$ Department of Clinical Pharmacology, \\ ${ }^{3}$ Department of General and Bioorganic Chemistry of Kursk State Medical University, Kursk}

The purpose of the work was to assess the influence of a phenotype of oxidative metabolism on intensity of pharmacodynamic effect of the multistage hypotensive therapy administered to patients with arterial hypertension of high and very high risk. The research included 120 patients with arterial hypertension of 2-3 degrees. The high risk of developing cardiovascular complications was detected in 58 people $(48.3 \%)$, very high - in 62 patients $(51.7 \%)$. The results of the conducted research showed the dependence of the degree of lowering arterial pressure on phenotypical option of oxidative metabolism estimated after 14-week treatment of patients with arterial hypertension with various schemes of multistage hypotensive therapy including amlodipin as a starting drug. This fact enables to make the individualized choice of initial option of pharmacotherapy for patients with arterial hypertension.

Keywords: arterial hypertension, pharmacokinetics, combined pharmacotherapy.

Персонализация фармакотерапии сердечнососудистых заболеваний является одной из актуальных проблем кардиологии. Среди направлений персонификации лекарственного лечения заболеваний системы кровообращения весьма перспективным является использование фармакокинетического подхода. Последний позволяет определить межиндивидуальные различия кинетики лекарственных препаратов и оптимизировать фармакотерапию с учетом этих различий $[1,8,9,10$, $11,12,14]$. Среди основных классов гипотензивных препаратов есть лекарственные вещества, фармакодинамический эффект которых определяется, в частности, генетически детерминированным полиморфизмом их биотрансформации. К числу таких препаратов относится амлодипин представитель дигидропиридиновых блокаторов кальциевых каналов (БКК). Известно, что амло- дипин метаболизируется изоферментами подсемейства цитохрома P450 (СҮР)3А в печени. Активность последних может значительно варьировать у различных людей и определять в конечном итоге различия в эффективности и переносимости амлодипина $[10,15,16]$.

В то же время пациенты с артериальной гипертонией $(\mathrm{AГ})$ высокого и очень высокого риска нуждаются в применении комбинированной антигипертензивной терапии. В связи с этим представляется важным изучение вклада полиморфизма биотрансформации лекарственных средств в выраженность суммарного фармакодинамического эффекта комплексной гипотензивной терапии у больных АГ.

Целью работы являлась оценка влияния фенотипа окислительного метаболизма на выраженность фармакодинамического эффекта многосту- 
пенчатой гипотензивной терапии, проводимой у больных артериальной гипертонией высокого и очень высокого риска.

\section{МАТЕРИАЛЫ И МЕТОДЫ ИССЛЕДОВАНИЯ}

В исследование было включено 120 больных артериальной гипертонией 2-3 степени, имеющих критерии высокого и очень высокого риска развития сердечно-сосудистых осложнений [5].

Критериями исключения из исследования были: наличие порока сердца, инфаркта миокарда, инсульта, стабильной стенокардии напряжения III-IV ФК в период обследования или в анамнезе; наличие хронической сердечной недостаточности III-IV ФК; нарушение ритма и проводимости сердца, требующие антиаритмической терапии; симптоматическая АГ; наличие хронической бронхолегочной патологии, сахарного диабета; сопутствующая патология, требующая постоянной медикаментозной терапии.

В основной группе мужчины составили $70 \%$ (84 чел.), женщины - 30\% (36 чел.). Среднее значение возраста пациентов составляло 63,0 (58,0$64,0)$ года. Длительность артериальной гипертонии $-10,60 \pm 2,89$ года. Среди включенных в исследование больных превалировали лица с 3 степенью АГ (95 чел. - 79,1\%), со 2 степенью было 25 пациентов $(20,9 \%)$. Высокий риск был определен у 58 чел. (48,3\%), очень высокий - у 62 больных $(51,7 \%)$.

Пациентам, удовлетворяющим критериям включения в основную группу, в течение трехдневного плацебо-периода проводили клинические, лабораторные и инструментальные методы исследования, после чего пациенты были рандомизированы по трем группам, отличавшимся схемами фармакотерапии. Критериями рандомизации служили: пол (мужчины/женщины), возраст (45-55; 55-65 лет), степень АГ (2, 3 степень), наличие или отсутствие стабильной стенокардии напряжения, функциональный класс ХCH (I, II ФК). В скрининговом периоде при необходимости пациенты могли использовать каптоприл.

Для стартовой фармакологической коррекции АГ использовали следующие варианты второй ступени лечения: 1-я группа - амлодипин 5-10 мг/сут (нормодипин, ОАО «Гедеон Рихтер», Венгрия) + рамиприл 5-10 мг/сут (амприлан, АО «КРКА», Словения); 2-я группа - амлодипин 5-10 мг/сут (нормодипин, ОАО «Гедеон Рихтер», Венгрия) + лизиноприл 10-20 мг/сут (диротон, ОАО «Гедеон Рихтер», Венгрия); 3-я группа фиксированная комбинация амлодипина и лизиноприла (экватор 1 табл. (5+10 мг)/сут - 1 табл. $(10+20$ мг)/сут, ОАО «Гедеон Рихтер», Венгрия).
На 3-й ступени лечения назначали бисопролол 5-10 мг/сут (бидоп, ОАО «Гедеон Рихтер», Венгрия), на 4-й ступени - индапамид 1,5 мг/сут (индапамид МВ ШТАДА, «Макиз-Фарма ООО», Россия).

В каждой из 3 групп проводили титрование доз препаратов, критерием увеличения которых было отсутствие достижения целевого (менее 140/90 мм рт. ст.) артериального давления (АД), оцениваемого при очередном визите пациента через каждые 2 нед. Продолжительность подбора доз препаратов на 2-й и 3-й ступенях лечения составляла 4 недели (для каждой ступени), общая длительность наблюдения - 14 недель.

Определение фенотипа окислительного метаболизма проводили методом высокоэффективной обращенно-фазовой жидкостной хроматографии (хроматоргаф «Милихром», НПО «Научприбор», РФ) с использованием ранее описанной методики оценки фармакокинетических параметров препарата-маркера в биожидкости $[4,7]$. Верифицирующим показателем для определения фенотипа окислительного метаболизма служил период полувыведения $\left(\mathrm{T}_{1 / 2}\right)$ препарата-маркера. Фенотип окислительного метаболизма оценивали по следующим граничным уровням $\mathrm{T}_{1 / 2}$ : менее 9 час - пациенты с быстрым фенотипом окислительного метаболизма; значения от 9 до 15 час - лица с медленным фенотипом; при значении периода полуэиминации более 15 час - больные с очень медленной скоростью окислительного метаболизма.

Перед проведением статистической обработки полученных показателей, проводили оценку принадлежности исследуемых параметров к нормальному распределению. При нормальном распределении изучаемые параметры описывали с помощью их среднего значения (M) и стандартного отклонения (SD). При отличном от нормального распределении показателей, их описание осуществляли с помощью медианы $(\mathrm{Me})$ и межквартильного интервала (нижний - $25 \%$ и верхний - 75\% квартили). Количественные показатели оценивали с помощью t-критерия (критерий Стьюдента) для независимых и зависимых переменных. При отличном от нормального распределении переменных достоверность различий оценивали с помощью непараметрических методов Вилкоксона и Манна-Уитни (для зависимых и независимых переменных соответственно). Статистически значимыми считали различия при значениях двустороннего $\mathrm{p}<0,05$. Для устранения ошибочных оценок наличия достоверности различий параметров при множественном сравнении подгрупп применяли поправку Бонферрони. При сравнении дискретных величин в системе четырехпольных таблиц с помощью критерия $\chi^{2}$ последний оценивали с коррекцией на непрерыв- 
ность по Йетсу. При наличии в одном из полей таблицы $2 \times 2$ значения признака менее 5 , использовали точный критерий Фишера. Наличие и степень взаимосвязи между различными параметрами оценивались с помощью корреляционного анализа. Для оценки значимости влияния различных факторов на исследуемые показатели использовали дисперсионный анализ [2, 3].

\section{РЕЗУЛЬТАТЫ ИССЛЕДОВАНИЯ И ИХ ОБСУЖДЕНИЕ}

Частота применения различных ступеней гипотензивной терапии у больных исследуемых групп отражена на рис. 1. У пациентов третьей группы по сравнению с больными первой и второй групп чаще $(\mathrm{p}<0,01)$ применялась схема лечения, включавшая два антигипертензивных препарата.

Распределение обследованных пациентов по скорости окислительного метаболизма соответствовало тримодальному варианту, что было представлено в литературе ранее [4]. Степень снижения АД (модульные значения), достигнутая в каждой из трех групп вмешательства и подгруппах с различными фенотипами окислительного метаболизма, представлена в таблице 1.

Таблица 1

Степень снижения артериального давления у больных исследуемых групп, имеющих различные фенотипы окислительного метаболизма

\begin{tabular}{|c|c|c|c|c|c|c|c|}
\hline \multirow{3}{*}{$\begin{array}{c}\text { Группа } \\
\text { вмешательства }\end{array}$} & \multirow{3}{*}{ Показатели } & \multicolumn{3}{|c|}{ Фенотипические группы } & \multicolumn{3}{|c|}{$\mathrm{p}$} \\
\hline & & Б & $\mathrm{M}$ & OM & \multirow{2}{*}{$1-2$} & \multirow{2}{*}{$1-3$} & \multirow{2}{*}{$2-3$} \\
\hline & & 1 & 2 & 3 & & & \\
\hline \multirow{2}{*}{ 1-я группа } & $\triangle \%$ САД & $9,21(6,59-13,6)$ & $21,3 \pm 4,97$ & $25,7 \pm 6,02$ & $* * *$ & $* * *$ & нд \\
\hline & $\triangle \%$ МАД & $5,66(1,01-10,2)$ & $18,9 \pm 5,79$ & $27,3 \pm 7,99$ & $* * *$ & $* * *$ & $*$ \\
\hline \multirow{2}{*}{ 2-я группа } & $\triangle \%$ САД & $6,78(6,59-9,34)$ & $20,8 \pm 3,89$ & $28,7 \pm 3,46$ & $* * *$ & $* * *$ & $* * *$ \\
\hline & $\triangle \%$ ДАД & $9,90(1,04-13,8)$ & $21,2 \pm 7,61$ & $26,0 \pm 6,75$ & $* * *$ & $* * *$ & нд \\
\hline \multirow{2}{*}{ 3-я группа } & $\triangle \%$ САД & $12,1(8,85-17,6)$ & $30,9 \pm 3,01$ & $29,6 \pm 4,94$ & $* * *$ & $* * *$ & нд \\
\hline & 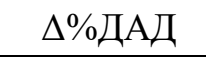 & $6,25(1,04-10,4)$ & $24,3 \pm 5,52$ & $28,3 \pm 6,89$ & $* * *$ & $* * *$ & нд \\
\hline
\end{tabular}

Примечание: здесь и далее: Б - быстрый фенотип окислительного метаболизма, М - медленный фенотип окислительного метаболизма, ОМ - очень медленный фенотип окислительного метаболизма. $\Delta \%$ САД - степень (\%) снижения систолического АД, $\Delta \%$ ДАД - степень (\%) снижения диастолического АД. Достоверность различий между фенотипическими группами: * - p $<0,05$; $* *-\mathrm{p}<0,01 ; * * *-\mathrm{p}<0,001$.

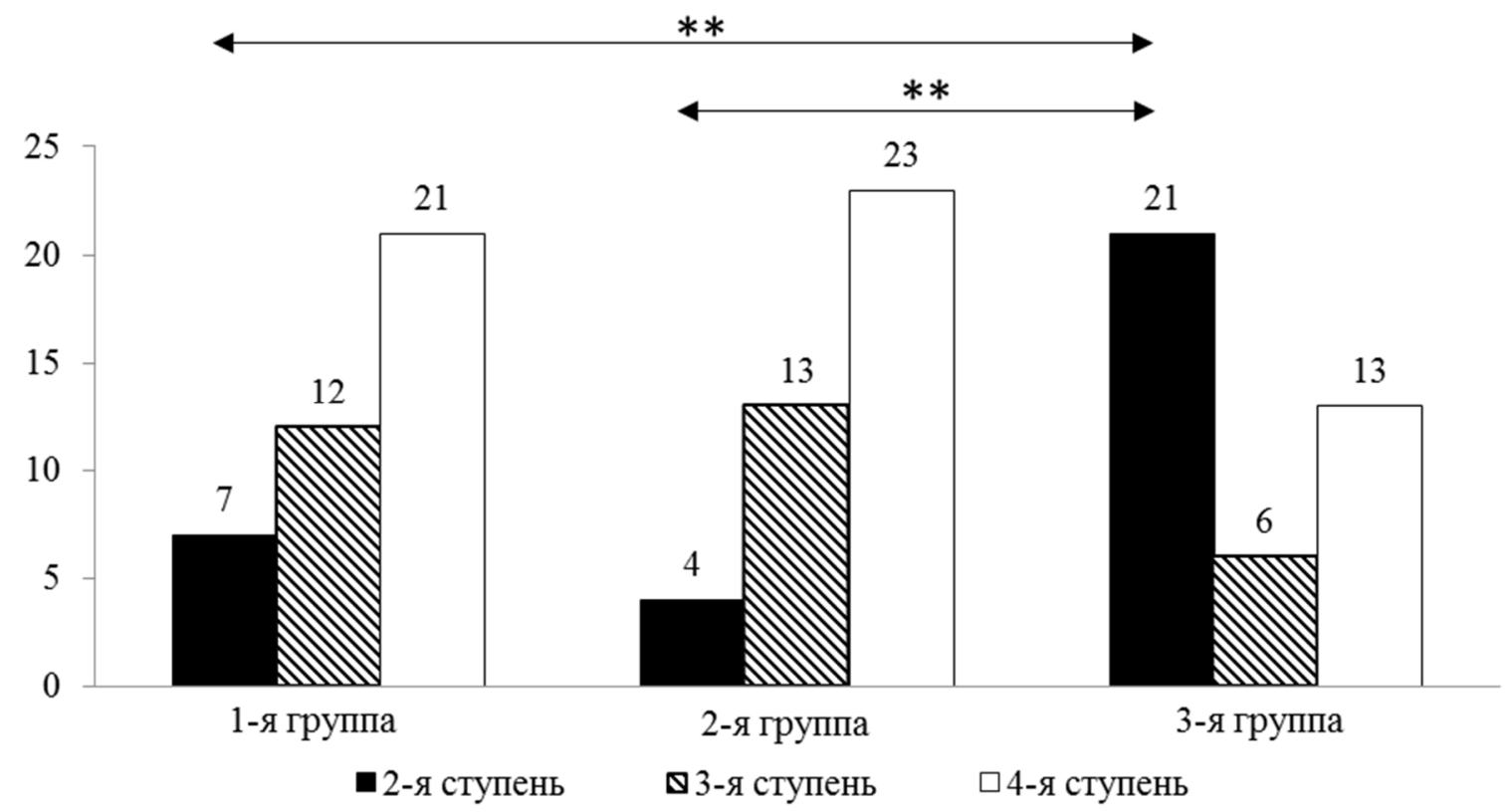

Рис. 1. Распределение больных первой, второй и третьей групп по ступеням гипотензивной фармакотерапии в конце 14 недели наблюдения. 


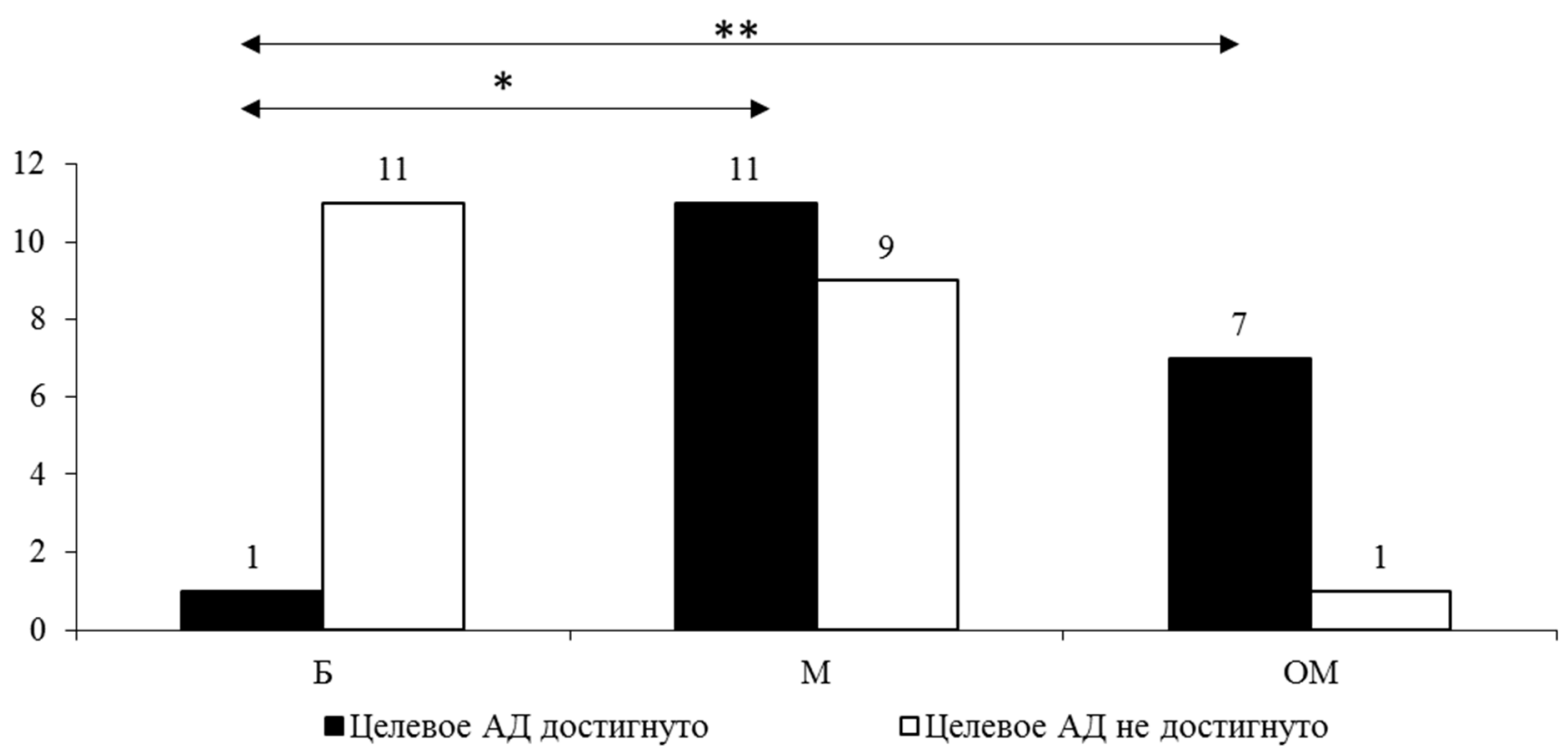

A.

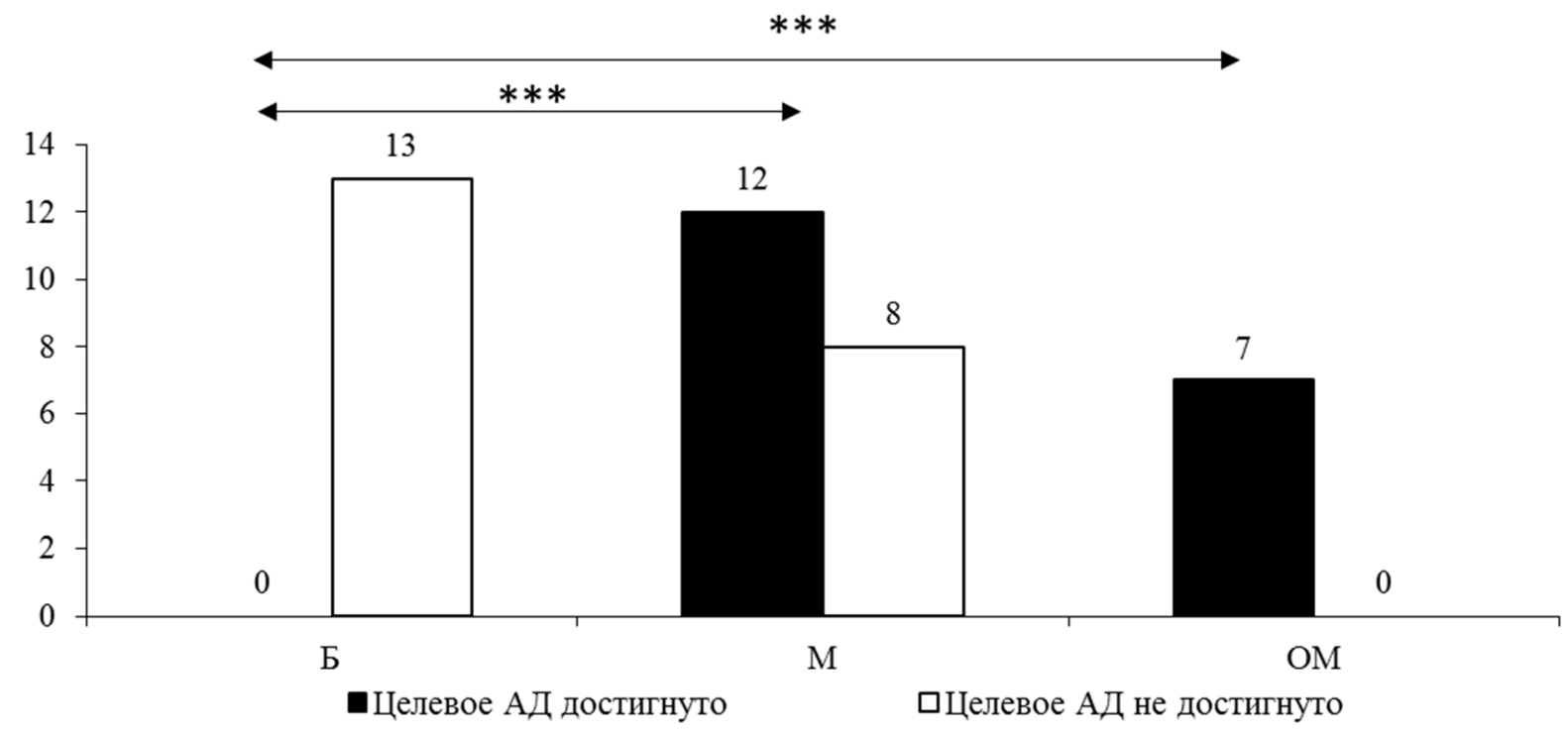

Б.

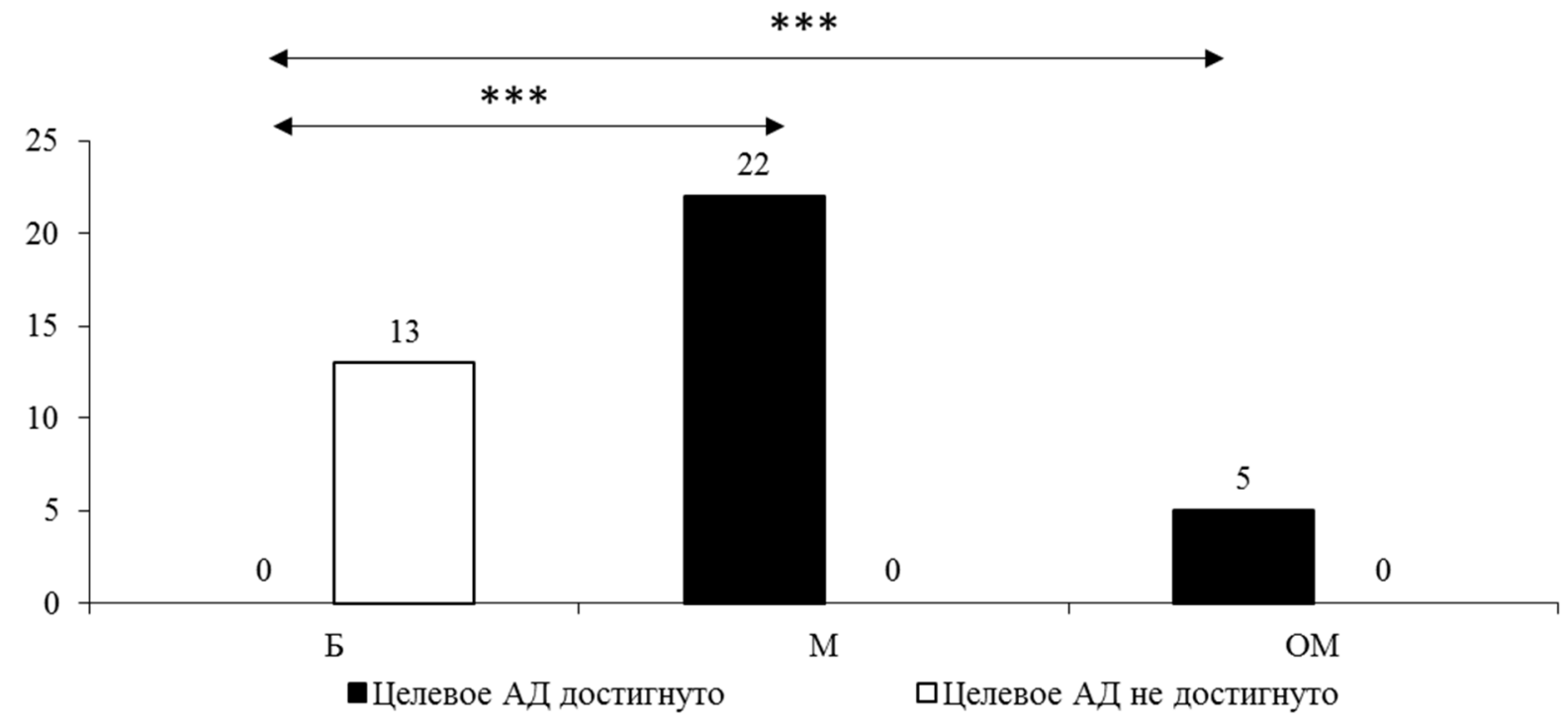

B.

Рис. 2. Частота достижения целевого АД в зависимости от фенотипа окислительного метаболизма у пациентов первой (А), второй (Б) и третьей (В) групп при 14-недельной фармакотерапии. 
Степень снижения АД у больных, имеющих медленный и очень медленный фенотипы окислительного метаболизма, в каждой из трех обследованных групп была достоверно больше, чем у пациентов с быстрым вариантом окислительного процесса. Первые две фенотипические подгруппы также значимо различались между собой по степени снижения диастолического АД (ДАД) у больных первой группы и по величине снижения систолического АД (САД) - у пациентов второй группы.

В каждой из трех исследуемых групп в конце наблюдения было зарегистрировано достоверное превалирование числа больных, имеющих целевой уровень АД, среди лиц с медленным и очень медленным фенотипом окислительного метаболизма по сравнению с пациентами, характеризующимися интенсивным процессом биотрансформации лекарственных препаратов (рис. 2). При этом частота достижения целевого АД была выше у пациентов третьей группы, имеющих медленный фенотип окислительных процессов, по сравнению с аналогичной когортой больных первой и второй групп ( $<<0,001$ и $p<0,01$ соответственно). Проведение аналогичного анализа в объединенных (медленный и очень медленный фенотипы окислительного метаболизма) когортах больных выявило идентичное вышеуказанному различие ( $\mathrm{p}<0,01$ и $\mathrm{p}<0,01$ соответственно).

Градации скорости окислительного метаболизма, рассматриваемые как детерминирующий фактор при проведении дисперсионного анализа, оказывали достоверное влияние на степень снижения САД и ДАД как в первой $(\mathrm{F}=21,6, \mathrm{p}<0,001$; $\mathrm{F}=31,6, \mathrm{p}<0,001$ соответственно), так и во второй ( $\mathrm{F}=100,8, \mathrm{p}<0,001 ; \mathrm{F}=19,1, \mathrm{p}<0,001$ соответственно), и третьей группах ( $\mathrm{F}=73,9, \mathrm{p}<0,001 ; \mathrm{F}=45,5$, $\mathrm{p}<0,001$ соответственно).

Проведенная с помощью корреляционного анализа оценка взаимосвязи $\mathrm{T}_{1 / 2}$ тест-препарата и степени антигипертензивного эффекта терапии у больных первой группы, установила достоверное влияние исследуемого параметра на $\Delta \%$ САД и $\Delta \%$ ДАД $(\mathrm{r}=0,59, \mathrm{p}<0,001 ; \mathrm{r}=0,69, \mathrm{p}<0,001$ соответственно). Аналогичная взаимосвязь имела место как во второй $(\mathrm{r}=0,86, \mathrm{p}<0,001 ; \mathrm{r}=0,58, \mathrm{p}<0,001$ соответственно), так и у пациентов третьей группы наблюдения $(\mathrm{r}=0,49, \mathrm{p}<0,01 ; \mathrm{r}=0,61, \mathrm{p}<0,001$ соответственно).

В проведенном исследовании возможность оценки влияния особенностей биотрансформации лекарственных средств на степень их гипотензивного эффекта была обусловлена как полимодальным распределением больных по скорости окислительного метаболизма, так и фармакокинетическими характеристиками применяемых в работе лекарственных препаратов. В частности, амлоди- пин являлся препаратом, фармакодинамический эффект которого зависел от фенотипа биотрансформационных окислительных процессов [10, $15,16]$. Амлодипин назначали в составе стартового лечения у всех больных и использовали далее на более высоких ступенях фармакотерапии. Ocновные пути биотрансформации остальных препаратов, применявшихся в работе, не совпадали с таковым у амлодипина $[6,11,17,19,20,22]$.

Проведенные расчеты подтвердили наличие статистически значимой зависимости степени снижения АД от фенотипа окислительного метаболизма. Последний, как факторная детерминанта, достоверно влиял на выраженность гипотензивного эффекта каждого из трех вариантов комбинированной терапии больных артериальной гипертонией. При этом у пациентов третьей группы, имеющих медленный и очень медленный фенотипы окислительного метаболизма (объединенная подгруппа), фиксированная комбинация амлодипина и лизиноприла в сочетании с бисопрололом и индапамидом оказывала достоверно более выраженный антигипертензивный эффект (по критерию достижения целевого АД) по сравнению с аналогичными когортами больных второй и первой групп. Это может свидетельствовать о преимуществе использования фиксированных сочетаний лекарственных средств в составе многоступенчатой фармакотерапии больных АГ.

Полученные в работе данные концептуально совпадают с литературными сведениями по рассматриваемой проблеме $[18,21]$. В то же время особенности метаболизма гипотензивных средств являются не единственными факторами, обусловливающими величину антигипертензивного эффекта. Последняя детерминируется также другими этапами фармакокинетики препаратов, фармакодинамическими характеристиками лекарственных средств, используемых в схемах комбинированной терапии, взаимодействием препаратов между собой на различных этапах их фармакокинетического и фармакодинамического процессов $[12,13]$. Вероятно, в проведенном исследовании, регистрация значимого влияния фенотипа окислительного метаболизма на выраженность гипотензивного эффекта многокомпонентной терапии больных АГ, была во многом обусловлена выбором конкретных лекарственных препаратов, имеющих определенные особенности фармакокинетики, не вызывающие существенного нивелирования вклада биотрансформационного полиморфизма в реализацию антигипертензивного действия комплексного лекарственного лечения пациентов с АГ.

Таким образом, проведенный анализ показал наличие зависимости степени снижения АД от фенотипического варианта окислительного мета- 
болизма, оцениваемой при 14-недельном лечении больных АГ различными схемами многоступенчатой гипотензивной терапии с включением амлодипина в качестве стартового препарата. Данный факт может быть рассмотрен как возможность индивидуализации выбора начального варианта фармакотерапии пациентов с $\mathrm{A} Г$, имеющих низкую скорость окислительного метаболизма.

\section{ЛИТЕРАТУРА}

1. Арчаков А.И., Лисииа А.В., Петушкова Н.А., Карузина И.И. Цитохромы Р-450, лекарственная болезнь и персонифицированная медицина. Часть 1 // Клиническая медицина. - 2008. - Т. 86, № 2. C. 4-8.

2. Боровиков В.П., Боровиков И.П. STATISTICA. Статистический анализ и обработка данных в среде Windows. - М. : Филинъ, 1998. - 608 с.

3. Глани С. Медико-биологическая статистика. - М. : Практика, 1999. - 429 с.

4. Гридина С.А., Григорьева Т.М., Поветкин С.В., Филиппенко Н.Г. Фармакокинетический подход к персонализации антигипертензивной фармакотерапии // Эффективная фармакотерапия. Кардиология и ангиология. $-2016 .-$ Т. 10, № 1. - С. 8-13.

5. Диагностика и лечение артериальной гипертензии (Рекомендации Российского медицинского общества по артериальной гипертонии и Всероссийского научного общества кардиологов) // Системные гипертензии. - 2010. - № 3. - С. 5-26.

6. Индапамид. [Электронный ресурс] // Википедия. Режим доступа: https://ru.wikipedia.org/wiki/ Индапамид, свободный (10.06.2017).

7. Калугин А.A., Степченко А.А. Взаимосвязь фенотипа окислительного метаболизма и клинической эффективности ингибиторов протонной помпы у больных гастроэзофагеальной рефлюксной болезнью // Вестник современной клинической медицины. - 2016. - № 1(9). - С. 31-36.

8. Клиническая фармакокинетика: теоретические, прикладные и аналитические аспекты: руководство / под ред. В.Г. Кукеса. - М. : ГЭОТАР-Медиа, 2009. -432 c.

9. Кукес В.Г. Метаболизм лекарственных средств. Научные основы персонализированной медицины. Руководство для врачей. - М. : ГЭОТАР-Медиа, 2008. - $304 \mathrm{c}$.

10. Морозова Т.Е., Сычев Д.А., Ших Н.В. Фармакогенетические подходы к прогнозированию эффективности и безопасности фармакотерапии артериальной гипертензии // Лечащий врач. - 2016. № 3. - С. 79-83.
11. Сычев Д.А., Раменская Г.В., Игнатьев И.В., Кукес В.Г. Клиническая фармакогенетика: учебное пособие. - М. : ГЭОТАР-Медиа, 2007. -248 с.

12. Сычев Д.А., Ших Н.В., Гришина Е.А., Калле Е.Г., Рыжикова Л.А., Морозова Т.Е. Антигипертензивная эффективность и безопасность амлодипина у больного с различными генотипами по полиморфному маркеру С3435T гена АВСВ1 // Клиническая фармакология и терапия. - 2017. - № 3. - С. 49-53.

13. Тимофеева А.В., Горюнова Л.Е., Хаспеков Г.Л., Ковалевский Д.А., Скамров А.В., Булкина О.С., Талиџкий К.А., Карпов Ю.А., Бибилашвили Р.Ш. Фармакогенетика, фармакогеномика в свете проблем, связанных с эссенциальной артериальной гипертонией // Кардиологический вестник. 2007. - T. II, № 1. - C. 5-12.

14. Холодов Л.Е., Яковлев В.П. Клиническая фармакокинетика. - М. : Медицина, 1985. - 464 с.

15. Amlodipine. [Электронный pecypc] // Drugbank.ca. Режим доступа: http://www.drugbank.ca/drugs/DB00381, свободный (10.06.2017).

16. Beresford A.P., McGibney D., Humphrey M.J. Metabolism and kinetics of amlodipine in man // Xenobiotica. - 1988. - Vol. 18, N 2. - P. 245-254.

17. Indapamide. [Электронный pecypc] // Drugbank.ca. Режим доступа: http://www.drugbank.ca/drugs/DB00808, свободный (10.06.2017).

18. Kim K.A., Park P.W., Park J.Y. Effect of ABCB1 (MDR1) haplotypes derived from G2677T/C3435T on the pharmacokinetics of amlodipine in healthy subject // Br J Clin Pharmacol. - 2007. - Vol. 63, N 1. - P. 53-58. - doi: 10.1111/j.13652125.2006.02733.x

19. Leopold G. Balanced pharmacokinetics and metabolism of bisoprolol. // J. Cardiovasc Pharmacol. - 1986. - N 8 (Supp 1.11). - P. 16-20.

20. Lisinopril. [Электронный pecypc] // Drugbank.ca. Режим доступа: http://www.drugbank.ca/drugs/DB00722, свободный (10.06.2017).

21. Lynch A.I., Boerwinkle E., Davis B.R., Ford C.E., Eckfeldt J.H., Leiendecker-Foster C., Arnett D.K. Pharmacogenetic association of the NPPA T2238C genetic variant with cardiovascular disease outcomes in patients with hypertension // JAMA. - 2008. - Vol. 299, N 3. - P. 296-307. - doi: 10.1001/jama.299.3.296.

22. Ramipril. [Электронный pecypc] // Drugbank.ca. Режим доступа: http://www.drugbank.ca/drugs/DB00178, свободный (10.06.2017). 